\title{
Evaluation of the Results of Supermaximal Monocular Recession-Resection Operations for Large-Angle Sensory Exotropia
}

\author{
DOAA AHMED NAIEM, M.B.B.Ch.; HEBA MOHAMMED SHAFIK, M.D.; \\ MOHAMMED ASHRAF EL-DESOUKY, M.D. and AHMED LOTFI ALI, M.D.
}

The Department of Ophthalmology, Faculty of Medicine, Tanta University

\begin{abstract}
Background: In sensory exotropia with large distant angle ( $>40$ PD) there is usually preference to operate on the poorly seeing eye to spare the sound eye.

Aim of Study: To evaluate the results of monocular super maximal recession and resection operations performed on the poorly seeing eye.

Patients and Methods: The study was carried out in Ophthalmology Department, Tanta University Hospital included 30 patients had large angle sensory extropia (40 to 120 PD). We underwent full history taking, and required clinical ophthalmological and general examination.

Operations and Follow-up: Lateral rectus recession ranged from 7 to $11 \mathrm{~mm}$ and medial rectus resection ranged from 5 to $9 \mathrm{~mm}$. Postoperatively, follow-up was carried out after 1 week, 1, 3 and 6 months.

Results: Post operative persistently narrowed palpebral fissure was observed in 4 patients $(13.3 \%)$, while transient (for 3 months) limitation of abduction was observed in 4 patients $(13.3 \%)$. Postoperative orthotropia occurred in 23 cases $(76.7 \%)$ while residual exotropia was observed in 7 cases. After 6 months of follow-up recurrence occurred in $20 \%$. The operation was considered totally successful in 18 patients $(60 \%)$ who were with no residual exotropia, no recurrence, no persistent palpebral fissure narrowing, and no persistently limited abduction. Our patients' satisfaction had been obtained in 26 patients $(86.7 \%)$.

Conclusions and Recommendations: Monocular super maximal recession/resection operations on the affected eye could be a suitable decision in large angle sensory exotropia with acceptable rate of success and disfigurement and recurrence rates. More studies are recommended on larger numbers of patients and with longer period of follow-up. Also super maximal recession/resection operations can be tried on patients with large angle sensory esotropia.
\end{abstract}

Key Words: Sensory - Exotropia - Super maximal operation - Strabismus - Amblyopia.

Correspondence to: Dr. Doaa Ahmed Naiem, The Department of Ophthalmology, Faculty of Medicine, Tanta University

\section{Introduction}

SENSORY exotropia is a unilateral divergent misalignment of the eyes, resulting from loss of vision or longstanding poor vision in one eye. The angles are characteristically large, ranging from 30 to 100 prism diopters (A) and increase gradually over time, as long as the cause of visual deficit remains active [1]. Large-angle strabismus has been defined differently by various reviewers. An angle of 404 was selected [2], as the cutoff for defining large-angle strabismus. Sensory strabismus is seen in 5-9\% of strabismic patients [3]. Kim et al., [4] stated that sensory exotropia is more common than sensory esotropia particularly if the error of refraction in the fixing eye was myopia rather than emmetropia or hyperopia.

In cases of exotropia with large exodeviation angle, a 3 or 4 muscle surgery on both eyes is a rational option [5]. But, in patients with sensory exotropia, there is usually a strong preference for a monocular procedure to avoid the exposure of the dominant eye to the inherent risks of a surgical procedure surgery [5]. Furthermore, monocular surgery may preserve some muscles if a repeated operation is required. It may also help to and may reduce surgical time [2]. Several studies were done and have shown that it is safe to perform supermaximal amounts of recession without causing significant limitation of ocular movements or disfigurement [6-10]

\section{Patients and Methods}

The present study was carried out in Ophthalmology Department of Tanta University Hospital between January 2017 and January 2018, on 30 patients (17 females and 13 males) aging 5 to 47 
years (mean 26.0 \pm 12.3 ), with large angle sensory extropia (preoperative distant angle of deviation ranged from 40 to $120 \mathrm{PD}$ with a mean of $62.33 \pm$ 20.457 PD) fulfilling the criteria of study inclusion.

\section{Inclusion criteria:}

Monocular low vision or loss of vision due to congenital or acquired causes. Exodeviation of the poorly seeing eye. Large-angle exotropia defined in this study as an angle of deviation of $40 \Delta$ or greater.

\section{Exclusion criteria:}

- Patients with exotropia other than sensory type (alternating exotropia, intermittent exotropia, restrictive exotropia, paralytic exotropia, consecutive exotropia)

- Patients with an exodeviation angle less than 40 $\Delta$.

- Any patients with large A or V patterns, nystagmus, history of botulinum toxin injections for strabismus, or previous use of adjustable sutures.

- Nystagmus.

The aim was to evaluate the results of super maximal recession and resection operations performed on the poorly seeing eye, sparing the dominant seeing eye in these patients. Methods: Full history taking (including the age at the time of operation, and etiology of visual loss), visual acuity and fundus examination of both eyes, post cycloplegic refraction of both eyes, examination of ocular motility, measurement of the angle of exodeviation by Hirschberg test, prism and cover test. General medical assessment of the patient. Operative procedure: Monocular super maximal recession / resection operations were done for our patients according to their clinical situation and the distant angle of exodeviation according to Kushner, (2009) [11]. Lateral rectus recession ranged from 7 to $11 \mathrm{~mm}$ (mean $9.47 \pm 0.86$ ) and medial rectus resection ranged from 5 to $9 \mathrm{~mm}$ (mean $6.07 \pm 0.64$ ). Follow-up: Postoperatively, follow-up was carried out on first day following the operation, after 1 week, after 1 month, after 3 months and after 6 months. Statistical program SPSS version 24 Package was used for data analysis.

\section{Results}

Our patients' satisfaction has been obtained in 26 patients $(86.7 \%)$ and was significantly associated with achievement of total success, absence of residual exotropia, and absence of exotropia recur- rence. Patients' satisfaction in our studied cases showed a non significant relationship with limited abduction, narrowed palpebral fissure or early postoperative misalignment. No cases complained of diplopia and no enophthalmos has been observed in studied patients.

Table (1): Demographic and clinical data of studied cases.

\begin{tabular}{lc}
\hline Parameter & Number \\
\hline Sex: Female/Male & $17 / 13$ \\
VA in affected eye: & \\
$\quad$ Can't Be tested & 3 \\
Less than 6/60 & 23 \\
More than 6/60 & 4 \\
Fundus examination of affected eye: & 12 \\
Abnormal & 14 \\
Normal & 4 \\
Can't be seen & \\
Preoperative distant angle measurement $(\Delta):$ & 24 \\
40 to <80 D & 6 \\
80-120 D & \\
Cause of exotropia according to etiology: & 10 \\
Anterior segment pathology & 12 \\
Posterior segment pathology & \\
Amblyopia & \\
\hline
\end{tabular}

Table (2): Preoperative criteria of studied patients.

\begin{tabular}{lllll}
\hline & N & Min & Max & Mean \pm SD \\
\hline Age of the patient & 30 & 5 & 47 & $26.00 \pm 12.351$ \\
Age of exotropia onset & 30 & 1 & 43 & $20.13 \pm 11.175$ \\
Duration of exotropia & 30 & 1 & 30 & $5.87 \pm 6.811$ \\
Preoperative distant & 30 & 40 & 120 & $62.33 \pm 20.457$ \\
$\quad$ angle degree ( ) & & & & \\
Amount of surgery: & & & & \\
$\quad$ LR recession & 30 & 7 & 11 & $9.47 \pm 0.860$ \\
$\quad$ MR resection & 30 & 5 & 9 & $6.07 \pm 0.640$ \\
\hline
\end{tabular}

Table (3): Correlations between studied variables.

\begin{tabular}{|c|c|c|c|c|c|c|}
\hline & Onset & Age & Duration & $\begin{array}{c}\text { Degree } \\
\Delta\end{array}$ & $\begin{array}{c}\mathrm{LR} \\
\text { recession } \\
\mathrm{mm}\end{array}$ & $\begin{array}{c}\mathrm{MR} \\
\text { resection } \\
\mathrm{mm}\end{array}$ \\
\hline Onset & & $0.842 * *$ & 0.256 & 0.231 & 0.373 * & 0.089 \\
\hline Age & $0.842 * *$ & - & $0.641^{* *}$ & $0.366^{*}$ & $0.638 * *$ & 0.284 \\
\hline Duration & 0.256 & $0.641 * *$ & _- & 0.248 & $0.687 * *$ & 0.335 \\
\hline Degree & 0.231 & $0.366^{*}$ & 0.248 & & $0.390 *$ & 0.121 \\
\hline $\begin{array}{l}\text { LR } \\
\text { recession }\end{array}$ & $0.373^{*}$ & $0.638 * *$ & $0.687^{* *}$ & $0.390^{*}$ & & $0.561 * *$ \\
\hline $\begin{array}{l}\text { MR } \\
\text { resection }\end{array}$ & 0.089 & 0.284 & 0.335 & 0.121 & $0.561 * *$ & \\
\hline
\end{tabular}



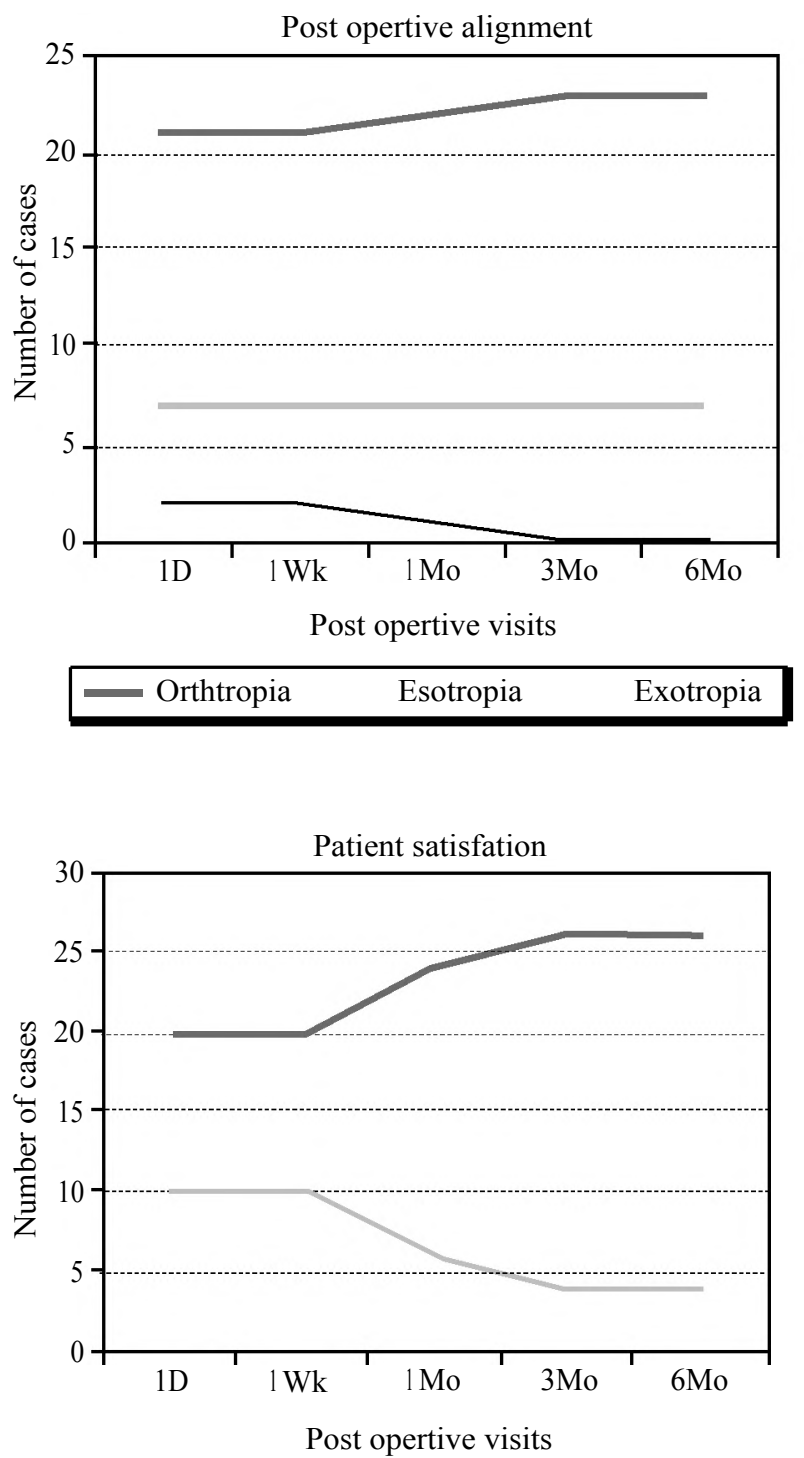

\begin{tabular}{|l|}
\hline Patient satisfied \\
Patient not satisfied
\end{tabular}
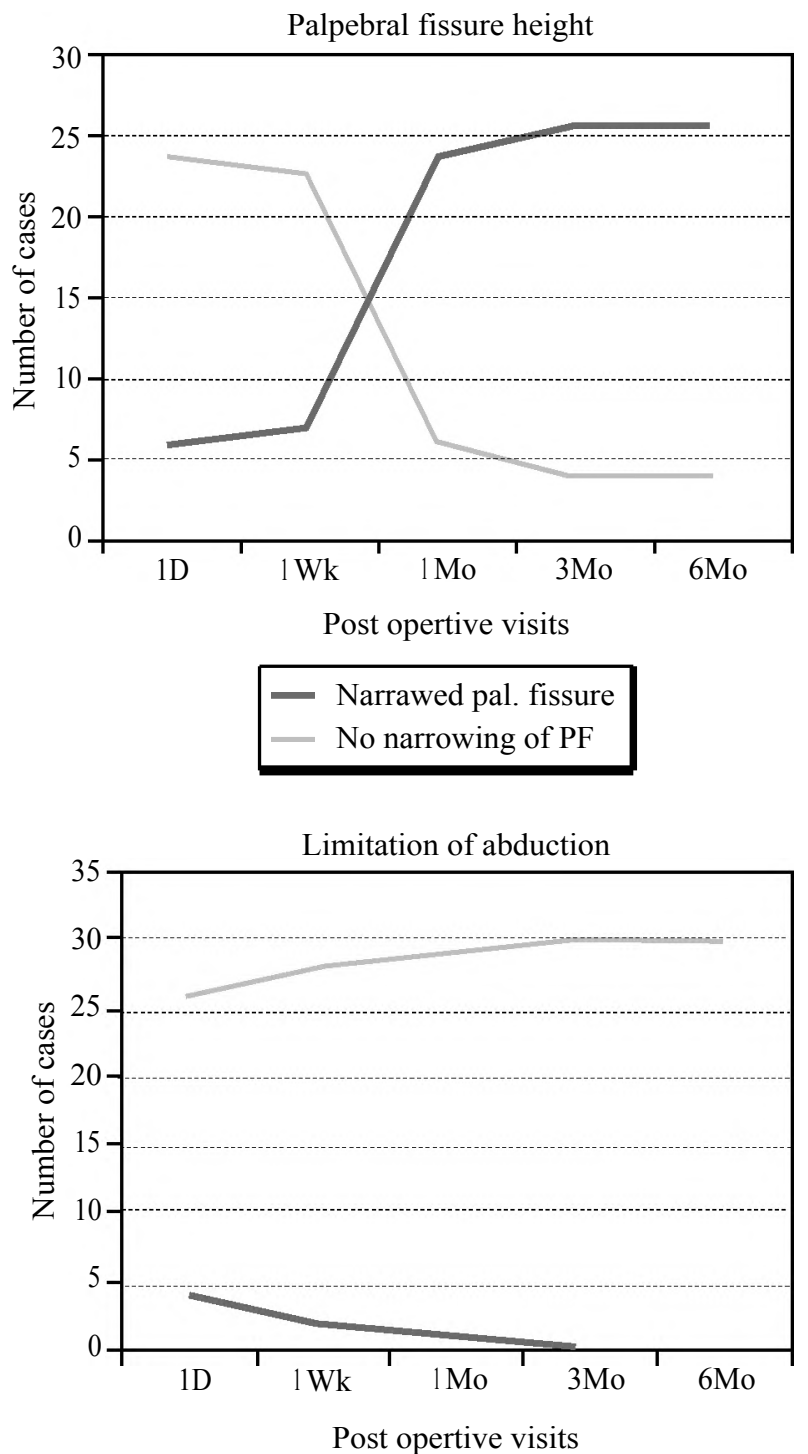

- Limited abduction
- Normal abduction

Fig. (1): Post operative follow-up of the studied patients.

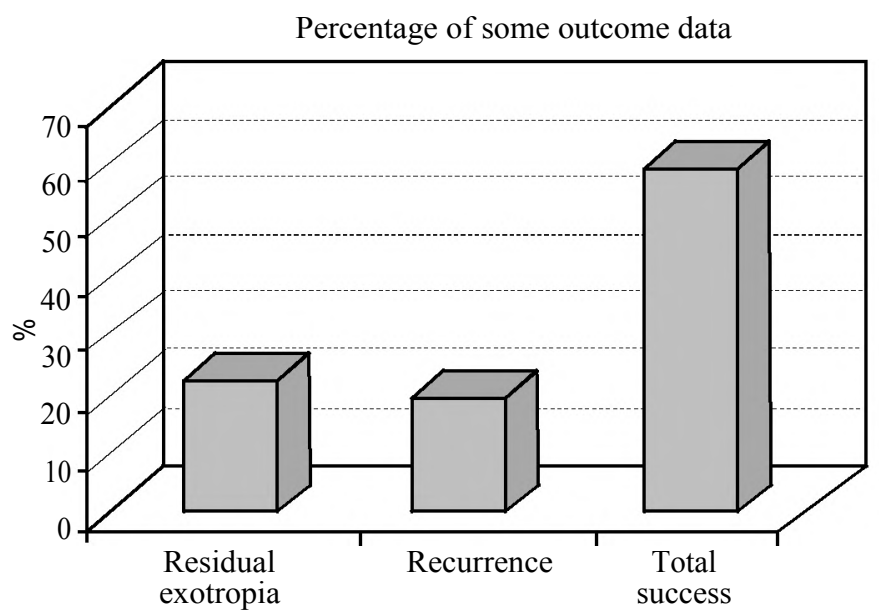

\section{Percent}

Fig. (2): Post operative outcome data after 6 months of follow-up 
Examples of cases:
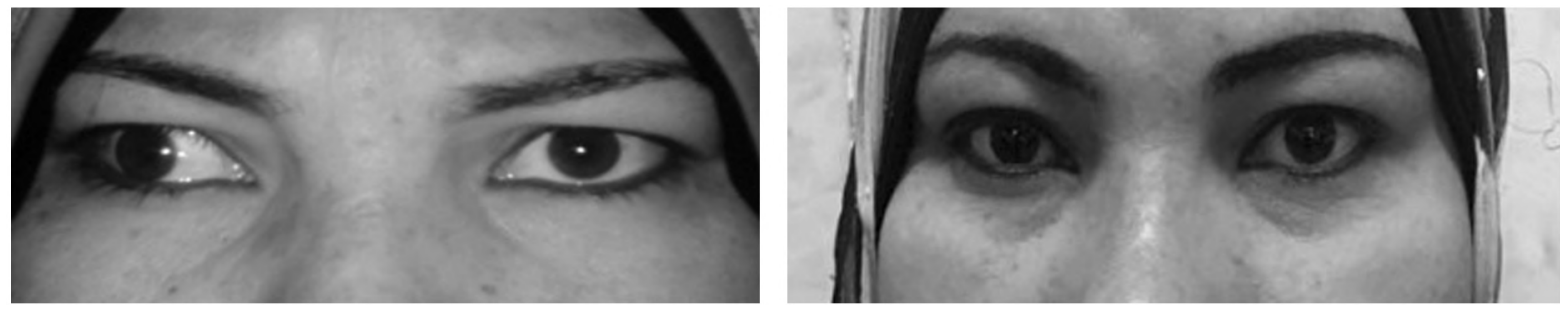

Fig. (3): Preoperative Rt sensory exotropia 604 Desecion LR recession $-9.00 \mathrm{~mm}$ MR resection $+6.00 \mathrm{~mm}$ Post operative follow-up showed orthotropia, no limited motility, normal palpebral fissure (Total success and satisfaction).
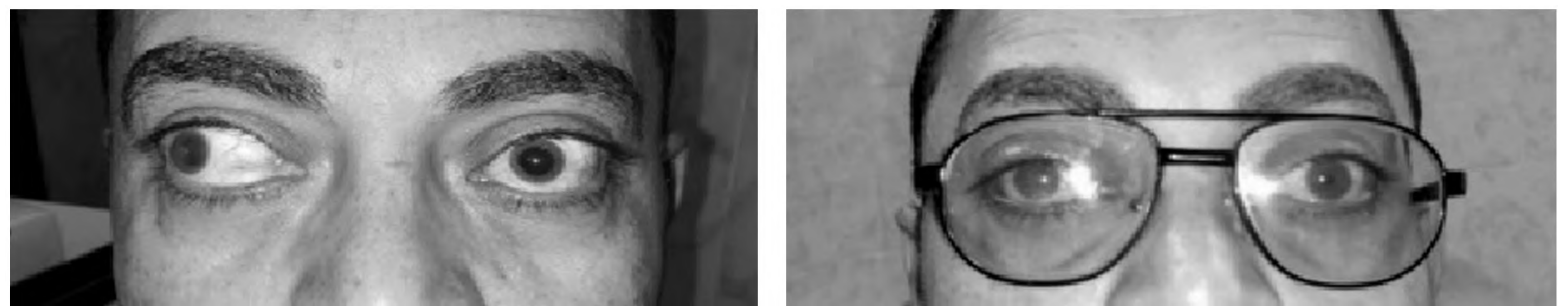

Fig. (4): Preoperative Rt sensory exotropia 804 Desecion LR recession $-11.00 \mathrm{~mm}$ MR resection $+7.00 \mathrm{~mm}$. Post operative follow-up showed residual exotropia 304 , limited motility early postoperative, transient narrow palpebral fissure (recurrence after 6 months).

\section{Discussion}

Postoperative persistently narrowed palpebral fissure was observed in 4 patients, while transient limitation of abduction was observed in 4 patients after one week, which disappeared within 3 months of follow-up. Post operative orthotropia occurred in 23 cases (76.7\%) with 2 cases of esotropia that improved within 3 months and residual exotropia was observed in 7 cases. During follow-up, exotropia in 6 patients, progressed again which could be considered as recurrence of exotropia ( $20 \%$ rate). In the present study persistent palpebral fissure narrowing after operation was significantly associated with higher amount of medial rectus resection. Chang et al., [5] coincided with our result, as they reported that the narrowing of palpebral fissure in their study was not disfiguring. Similarly, in our study the patient satisfaction was not significantly associated with palpebral fissure state following the operation. It was found that better visual acuity seemed to be a potential predictor for higher long-term success after strabismus surgery in patients with sensory strabismus [13]. The residual exotropia 6 months after operation was significantly associated with older age of the patient at the time of operation. The same result was reported in Gusekschneider and Boss study [13], where they found (in patients with perforating injury), a positive correlation between the residual postoperative angle in far distance and the older age at injury of the affected eye after long followup period of more than 5 years. In the study of
Millan et al., [2] all patients with preoperative deviation angles of $<65$ PD showed successful results of monocular surgery under local anesthesia, where those who had preoperative angles of 65 PD or more were not successful with post operative residual angles $>15 \mathrm{PD}$. Those failure cases underwent a second procedure with success of all cases.

It has been claimed that when more than a $6.00 \mathrm{~mm}$ medial rectus resection is performed, significant resistance to abduction, enophthalmos, and palpebral fissure narrowing can occur. A lateral rectus recession exceeding $7.00 \mathrm{~mm}$ to $8.00 \mathrm{~mm}$ is also said to reduce abduction significantly [13]. In the past it was thought that recessions that led to the muscle being placed behind the anatomical equator of the globe would cause limitation of ocular rotation $[7,15]$. Several previous studies of large-angle exotropia have reported success rates ranging from $72 \%$ to $80 \%$ in bilateral lateral rectus recessions, without significant abduction limitations $[\mathbf{6 , 7 , 8 , 1 0 , 1 5}$. Berland and Wilson, $[16]$ reported a success rate of $80 \%$ with a 8 to $9 \mathrm{~mm}$ bilateral lateral rectus recession, but with abduction limitations in $30 \%$ of the 24 patients studied. Bracamontes [17] supported bilateral surgery in large-angle exotropias in patients with low vision in one or both eyes, because the relapse rate is higher with monocular surgery. Furthermore, Currie, Shipman and Burke, [9] suggested that interventions involving three or four muscles in large-angle exotropia are more effective than surgery involving only two muscles. 
Regarding the presence of preoperative amblyopia, Thomas and Guha, [18] agreed with the present work in that patients who were amblyopic at the time of strabismus surgery had a poorer success rate of $33.33 \%$, compared to $68.42 \%$ success rate in the patients who did not have amblyopia at the time of surgery.

The operation was considered totally successful in 18 patients (60\%), with no residual exotropia, no recurrence, no persistent palpebral fissure narrowing, and no persistently limited abduction. By considering operative success as a postoperative exodeviation $10 \mathrm{PD}$ or less as in the protocol of this study, we could get an operative success rate in the present study in 23 patients out of 30 (76.7\%) which is a good rate compared with similar works on these high degrees of preoperative exodeviation (40-120 PD). In agreement with our results [19] reported that patients with a preoperative distant exodeviation > $40 \mathrm{PD}$ had a lower surgical success rate $(63.8 \%)$ than patients with a deviation $<40$ PD $(80 \%)$. The present work showed that total success was significantly associated with younger age of the patient at the onset of exotropia and at time of operation as well as with the less amount of lateral rectus recession.

\section{Conclusions and recommendations:}

It could be suggested that monocular supermaximal recession/resection operations on the affected eye could be a suitable decision in large angle sensory exotropia (distant angle of exodeviation 40-120 PD), with acceptable rate of success and non significant disfigurement and recurrence rates. The recurrence of exotropia after operation depended on 3 factors: Poorer visual acuity in the affected eye, presence of amblyopia as well as with larger preoperative distant angle of deviation. More studies are recommendedon larger number of patients and supermaximal recession/resection operations can be tried on patients with large angle sensory esotropia as well.

\section{References}

1- KRAFT S.P.: Selected exotropia entities and principles of management. In: Rosenbaum A.L., Santiago A.P., editors. Clinical strabismus management: Principles and surgical techniques. Philadelphia: W.B. Saunders, p. 1939, 1999.

2- MILLAN T., de CARVALHO K.M. and MINGUINI N.: Results of monocular surgery under peribulbar anesthesia for large-angle horizontal strabismus. Clinics., 64 (4): 303-308, 2009.
3- DAWSON E.L., SAINANI A. and LEE J.P.: Does botulinum toxin have a role in the treatment of secondary strabismus? Strabismus, 13 (2): 71-3, 2005.

4- KIM I.G., PARK J.M. and LEE S.J.: Factors Associated with the Direction of Ocular Deviation in Sensory. Horizontal Strabismus and Unilateral Organic Ocular Problems. Korean. J. Ophthalmol., 26 (3): 199-202, 2012.

5- CHANG J.H., KIM H.D., LEE J.B. and HAN S.H.: Super maximal Recession and Resection in Large-Angle Sensory Exotropia Korean. J. Ophthalmol., 25 (2): 139-141, 2011.

6- LIVIR-RALLATOS G., GUNTON K.B., and CALHOUN J.H.: Surgical results in large-angle exotropia. J. AAPOS, 6: 77-80, 2002.

7- SCHWARTZ R.L. and CALHOUN J.H.: Surgery of large angle exotropia. J. Paediatr. Ophthalmol. Strabismus, 17: 359-363, 1980.

8- CELEBI S. and KUKNER A.S.: Large bilateral lateral rectus recessions in large angle divergence excess exotropia. Eur. J. Ophthalmol., 11 (1): 6-8, 2001.

9- CURRIE Z.I., SHIPMAN T. and BURKE J.P.: Surgical correction of large angle exotropia in adults. Eye, 17: 334-339, 2003.

10- RAYNER J.W. and JAMPOLSKY A.: Management of adult patients with large angle amblyopic exotropia. Ann. Ophthalmol., 5: 95-9, 1973.

11- KUSHNER B.J.: Exotropic deviations In: Wilson M.E., Saunders R.A., and Trivedi R.H. (eds) Pediatric Ophthalmology Current Thought and A Practical Guide, Springer., 97-111, 2009.

12- TURAN K.E., ŞEKEROGLU H.T., ŞENER E.C. and SANAÇ A.S.: Effect of Visual Acuity on the Surgical Outcomes of Secondary Sensory Strabismus. Turk. J. Ophthalmol., 45: 254-258, 2015.

13-GUSEK-SCHNEIDER G. and BOSS A.: Results Following Eye Muscle Surgery for Secondary Sensory Strabismus. Strabismus, 18 (1): 24-31, 2010.

14- PARKS M.M. and PARKER J.E.: Atlas of strabismus surgery. Philadelphia: Harper \& Row, p. 6-23m 1983.

15- PARKS M.M.: Comitant exodeviations in children. In: Ocular Motility and Strabismus. Hagerstown, M.D., Harper \& Row, 113, 1975.

16- BERLAND J.E., WILSON M.E. and SAUNDERS R.B. Results of large $(8-9 \mathrm{~mm})$ bilateral lateral rectus muscle recessions for exotropia. Binocul Vis Strabismus Q., 13 (2): 97-104, 1998.

17- BRACAMONTES A.C.: ManejoQuirúrgico de la ExotropiaSecundaria. In: XII Congreso del ConsejoLatinoamericano de Estrabismo. Buenos. Aires., 173, 1996.

18- THOMAS S. and GUHA S.: Large-Angle Strabismus: Can a Single Surgical Procedure Achieve a Successful Outcome? Strabismus, 18 (4): 129-136, 2010.

19- CHALIFOUX E., ALKHARASHI M., SUPERSTEIN R., LOUIS M., BLAIS C., SABZEVARI S. and FLANDERS M.: Adjustable surgical treatment of adult exotropia: postoperative target angles and surgical success. Can. J. Ophthalmol., 51 (4): 254-7, 2016. 


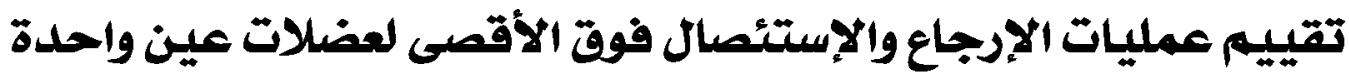

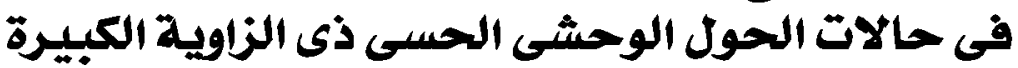

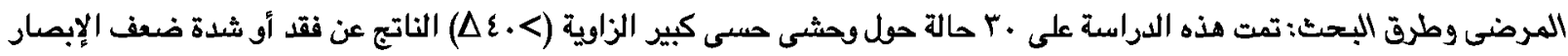

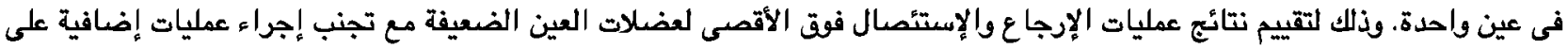

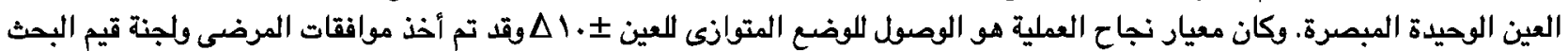
بكلية طب طنطا.

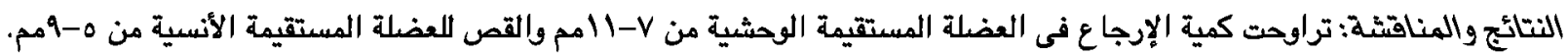

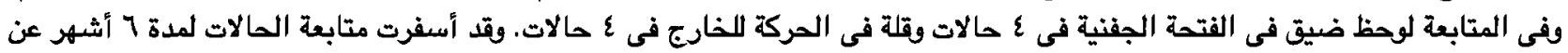

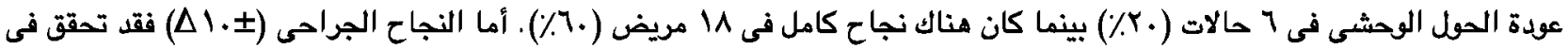

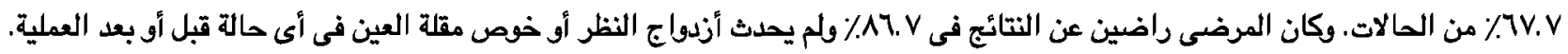

الأستتاج والتوصيات: يمكن أعتبار القص والإرجاع فقق الأقصى علاجاً مناسباً لحالات الحل الوحشى الحسى ذى الزاوية الكبيرة

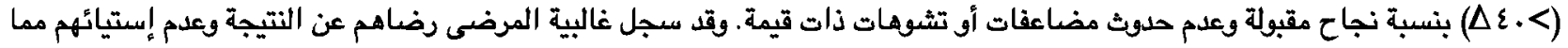

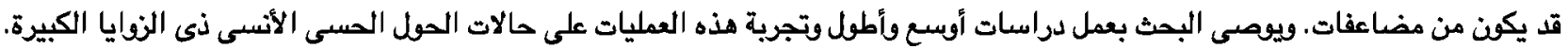

